\title{
Development of a Laser-Guided Deep-Hole Measuring System: Measurements of Roundness, Cylindricity and Straightness
}

\author{
Akio KATSUKI $^{1}$, Hiroshi MURAKAMI $^{2}$, Hiromichi ONIKURA ${ }^{1}$, Takao SAJIMA ${ }^{1}$ \\ ${ }^{1}$ Department of Intelligent Machinery and Systems, Faculty of Engineering, Kyushu University, Japan, \\ kaetr@mech.kyushu-u.ac.jp \\ ${ }^{2}$ Fukuoka Industrial Technology Center, Japan, hmurakami@fitc.pref.fukuoka.jp
}

\begin{abstract}
:
A measuring system is developed based on the autocollimation principle for evaluating the accuracy of a deep hole. The accuracy of a hole is measured by scanning its wall in a circumferential direction at depth intervals of $10 \mathrm{~mm}$ using a laser-guided probe. In this study, the accuracy and repeatability of this measuring system are evaluated by measuring the roundness, cylindricity and straightness of holes. As a result, it is clarified that the accuracy of the roundness, straightness, cylindricity measured by the measuring system corresponds well to that of the tester in terms of both shape and value and that the standard deviation of 10 measuring measurements of roundness is $0.19 \mu \mathrm{m}$.
\end{abstract}

Keywords: Deep hole, Measurement, Autocollimation principle, Laser diode

\section{Introduction}

Axial hole deviation produced by deep hole boring results in a degradation of quality and a reduction in the yield rate of products. A prototype 110-mm-diameter laser-guided deep-hole boring tool is developed to prevent hole deviation. The attitude of the tool is controlled by piezoelectric actuators [1]. After a deep hole is bored, an instrument is required that can evaluate the accuracy of the hole. It is very difficult to precisely measure the shapes of deep holes that have large length to diameter ratios $(L / D)$, e.g., a shaft of a jet engine, a cylinder for plastic injection molding, a cylinder liner of an engine for a large ship, or a cannon. Until now, the accuracy of various parameters of such holes is measured using different measuring devices. For example, the diameter, roundness and straightness of a hole are measured using a cylinder gauge, a roundness tester and an autocollimator, respectively.

Until now, several studies are conducted to measure the accuracy of holes. One study determines the accuracy of the hole by measuring the thicknesses of hole walls using a supersonic detector [2]. However, errors are produced while the thickness is measured by this supersonic detector and when a datum level for measurement is made on outside of the hole. Studies of measurement using a strain gauge and laser interferometer are also reported [3, 4]. However, large errors are produced using the strain gauge since it is based on an inferior measuring principle, and it is difficult to measure rough surfaces accurately using a laser interferometer.

To solve these problems a measuring system is developed based on the autocollimation principle [5]. Figure 1 shows this measuring system. This system consists of a probe and two optical systems, which are used for detecting the probe's position and inclination and for determining the guiding axis. The probe consists of a measuring unit, an actuator unit and a laser diode, which is located at the rear of the actuator unit. The laser diode is used to detect the position and inclination of the probe. The measuring unit is installed at the front of the actuator unit, which is guided by the laser.

In this study, we evaluate the performance of this measuring unit by using it to measure the roundness, cylindricity and straightness of holes.
(1) Probe

(2) Double disc coupling

(3) Optical system for measuring tool attitude

(4) Optical system for light reception
(5) Machine table

(6) Workpiece

(7) Guide bush

(8) Rotary encoder

(9) Measuring unit

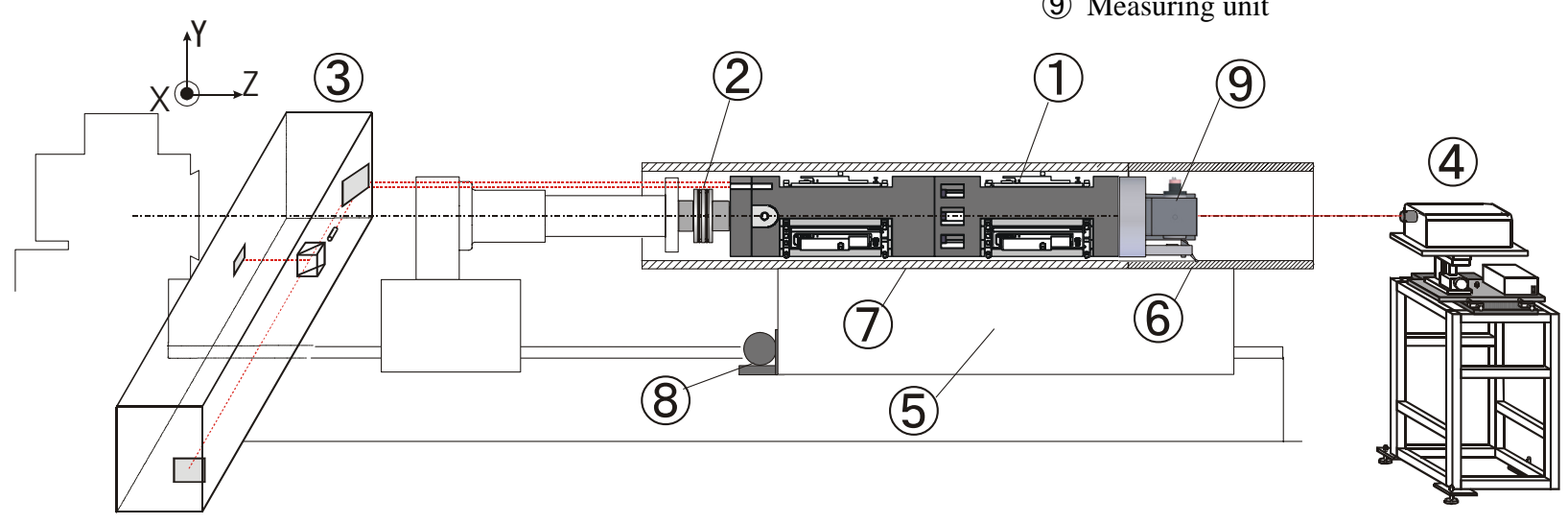

Figure 1: Measuring system. 


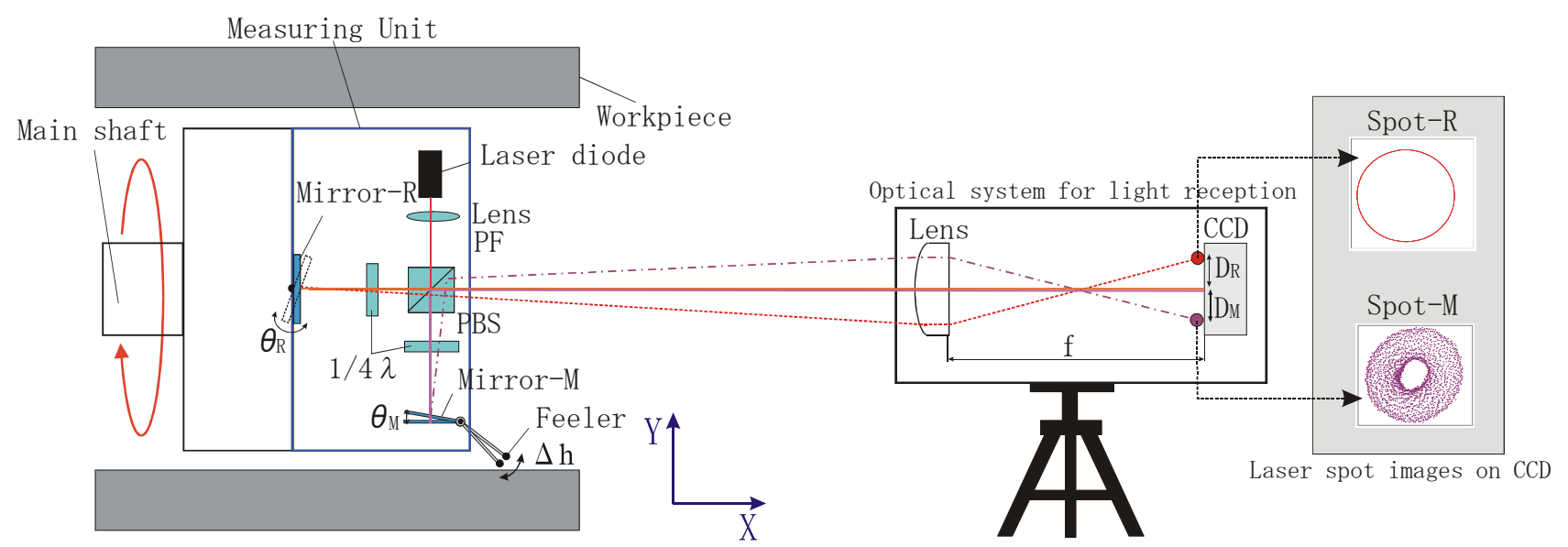

Figure 2: Measurement principle for determining the topography of a hole wall.

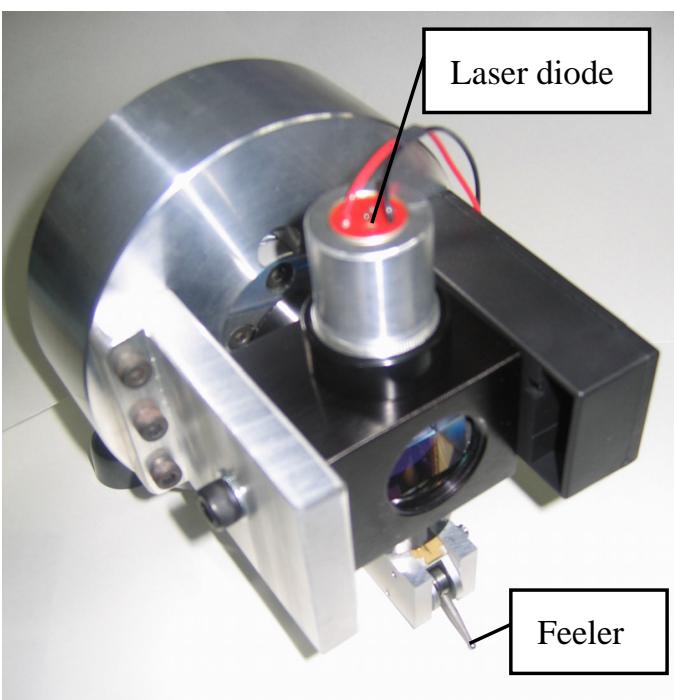

Figure 3: Measuring unit.

\section{Measuring Principle}

Figures 2, 3 and 4 show the measurement principle, the measuring unit and the optical system for light reception, respectively.

\subsection{Measuring Unit}

The measuring unit detects the displacement of a feeler on the basis of the autocollimation principle (Fig. 2). Mirror-M is used to measure the hole wall and is connected to the feeler. Mirror-R is used to determine the angle of rotation of the main spindle and is installed on a rotating axis. The laser beam passes through a polarizing beam splitter, where it is divided into transmitting and reflecting beams. These divided laser beams pass through 1/4-wave plates, and reach Mirror-M and Mirror-R that reflect them back towards the 1/4-wave plate. After passing through the $1 / 4$-wave plate, the beams reach the polarizing beam splitter and are reflected towards the measuring unit (i.e., in the direction of the $X$-axis).

\subsection{Optical System for Light Reception}

The optical system for light reception consists of a lens (plano-convex lens, focal distance $f=100 \mathrm{~mm}$ ) and a CCD camera (CS5110, teli) and it receives the laser beam

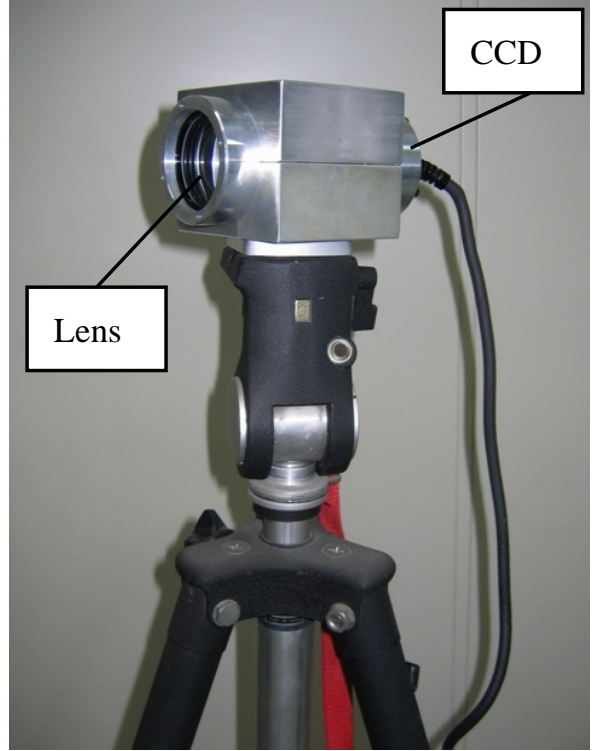

Figure 4: Optical system for light reception.

from the measuring unit. The CCD images of the laser beams reflected in the Mirror-M and Mirror- $\mathrm{R}$ are defined as Spot-M and Spot-R, respectively. The ratio of the intensities of the incoming light at Spots-M and $R$ is maintained at approximately $6: 4$ by adjusting the rotational angle of the two 1/4-wave plates. Regions containing a gray level of over 60 of the laser spot images on the CCD are labeled. There are thus two labeled regions, namely, Spot-M, which has a high luminance, and Spot-R, which has a low luminance. The two coordinates $(x, y)$ of Spots-M and -R on the CCD are obtained by calculating the center of gravity of the labeled regions. Spots-M and -R on the CCD are displaced in the optical system for light reception when the laser beam axis from the measuring unit is tilted. In other words, when the feeler of the measuring unit scans the hole wall and is displaced by an amount $\Delta h$ due to the profile of the wall, Mirror-M is tilted causing Spot-M to be displaced on the CCD (Fig. 2). Consequently, the location of the wall surface can be determined. In a similar manner, a slight tilting of Mirror-R causes Spot-R to be displaced. Spot-R revolves around the center of the $\mathrm{CCD}$ when the main spindle rotates. Consequently, the rotation angle and the inclination of the measuring unit can be obtained. 


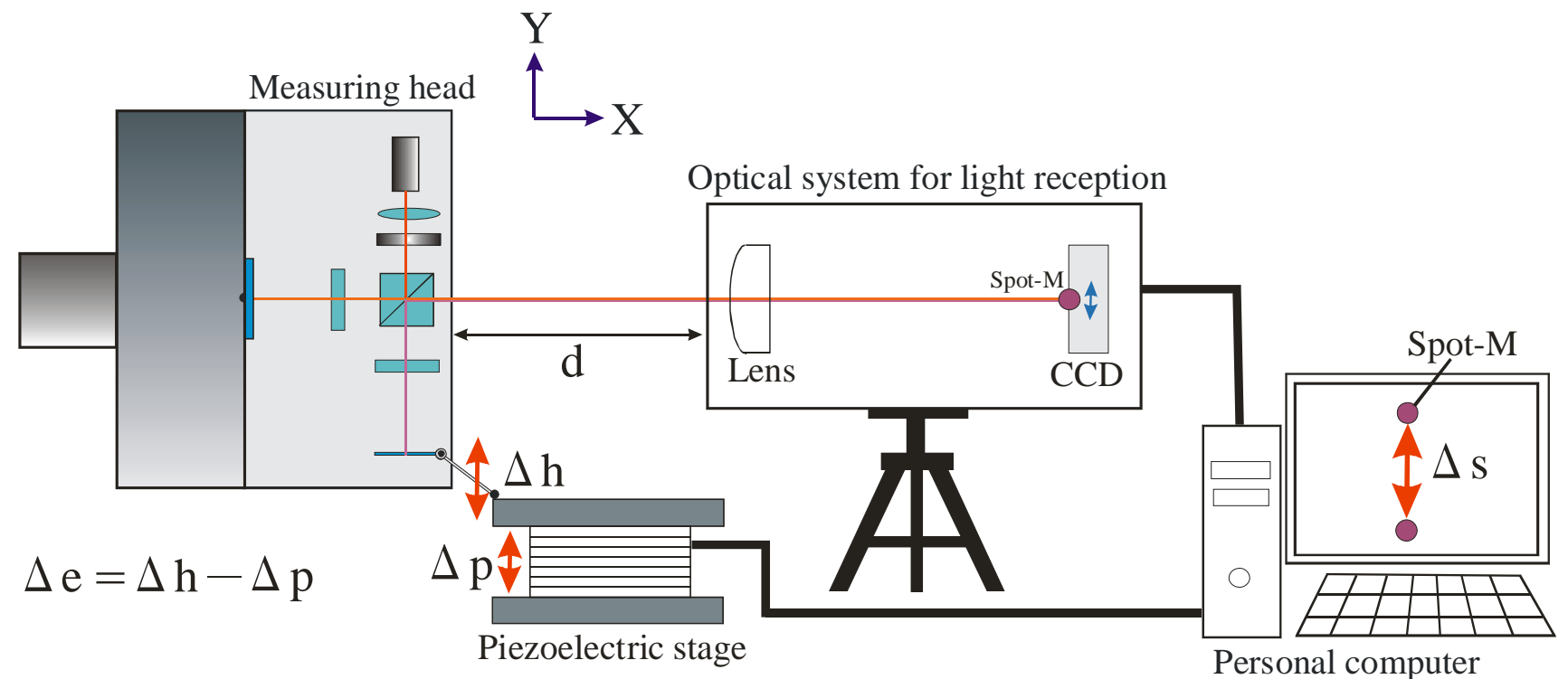

Figure 5: Experimental apparatus for evaluating measurement resolution.

$f$ is the focal distance of the lens. $D_{M}$ and $D_{R}$ are the distances between the focus (i.e., the center of the $\mathrm{CCD}$ ) and the image points of the laser beams reflected by the Mirror-M and Mirror-R, respectively. $\theta_{M}$ and $\theta_{R}$ are the tilting angles of Mirror-M and $-\mathrm{R}$, respectively. $D_{M}$ and $D_{R}$ can be expressed as follows:

$D_{M}=2 f \theta_{M}, D_{R}=2 f \theta_{R}$.

\section{Experimental Method and Results}

\subsection{Evaluation of the Measurement Resolution}

The measurement error is examined when the feeler is displaced by $1 \mu \mathrm{m}$. Figure 5 shows the basic experimental setup. The feeler is displaced in the $Y$-axis direction by the precision piezoelectric stage (P625.2CL, PI Co., Ltd., resolution: $1.4 \mathrm{~nm}$ ). This stage has a built-in capacitance-type displacement meter. The displacement of the stage is compared with the measured value by the measuring unit, and the difference between the two values is taken to be the measurement error.

Figure 6 shows the measurement error of the measuring unit. The horizontal axis shows the displacement of the feeler, while the vertical axis shows the deviation between the value measured by the displacement meter and that of the measuring unit. The standard deviation of this difference is $0.076 \mu \mathrm{m}$ over a measurement range of 0.25 $\mathrm{mm}$.

\subsubsection{Influence of the Measurement Distance}

Next, the same measurement is performed by maintaining the distance between the measuring unit and optical system for light reception at $600 \mathrm{~mm}$. The measurement error of the measuring unit is shown in Fig.7. The standard deviation of the difference is $0.089 \mu \mathrm{m}$ over a measurement range of $0.25 \mathrm{~mm}$, which confirms that the effect of measurement distance is negligible.

\subsubsection{Effect of the Image-processing Threshold}

Figure 8 shows the effect of the image-processing threshold on the error. The horizontal axis shows the

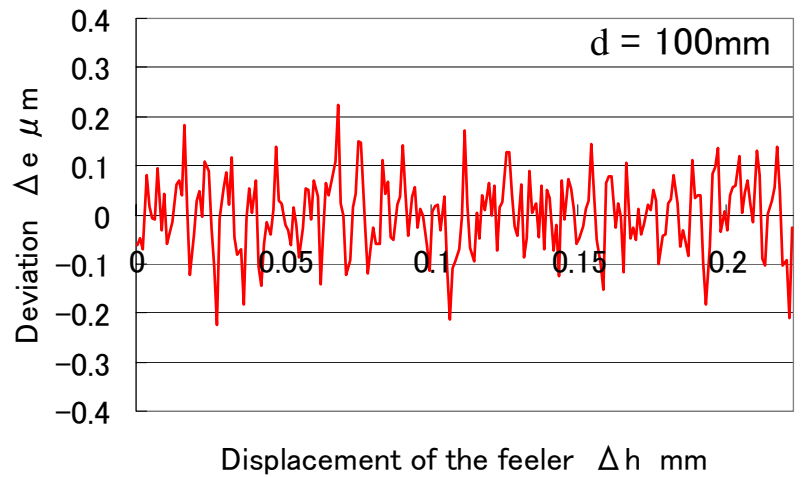

Figure 6: Measurement error of the measuring unit $(\mathrm{d}=100 \mathrm{~mm})$.

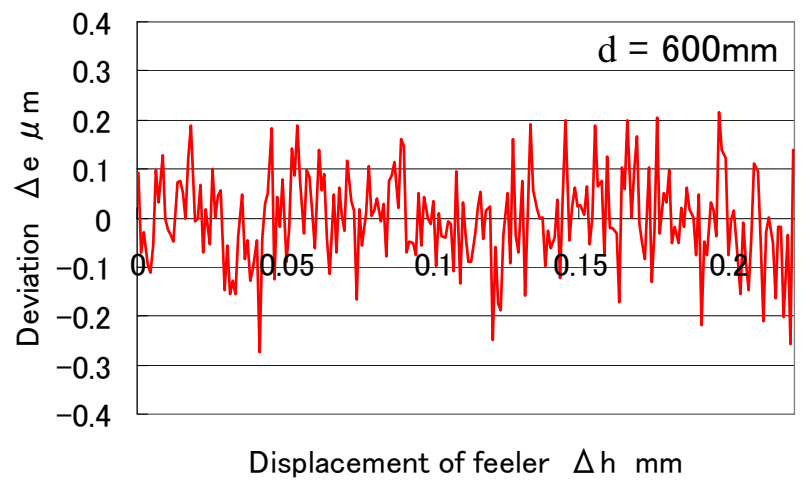

Figure 7: Influence of the distance $d$ on the measuring accuracy $(\mathrm{d}=600 \mathrm{~mm})$.

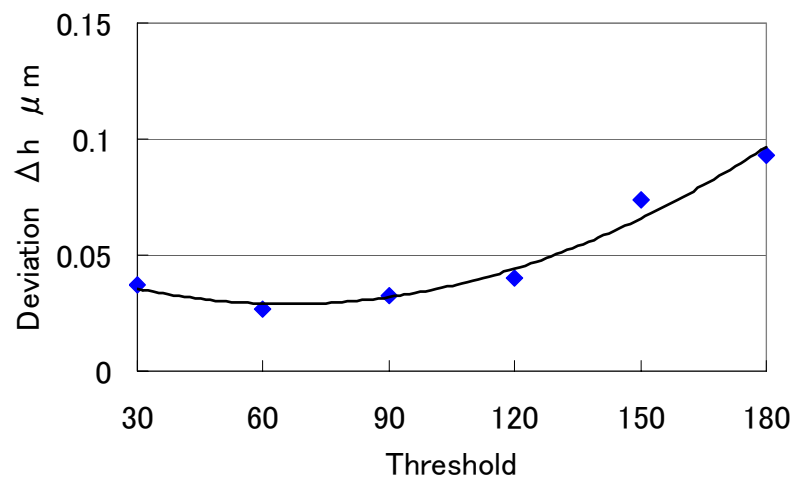

Figure 8: Effect of the image-processing threshold on the error. 


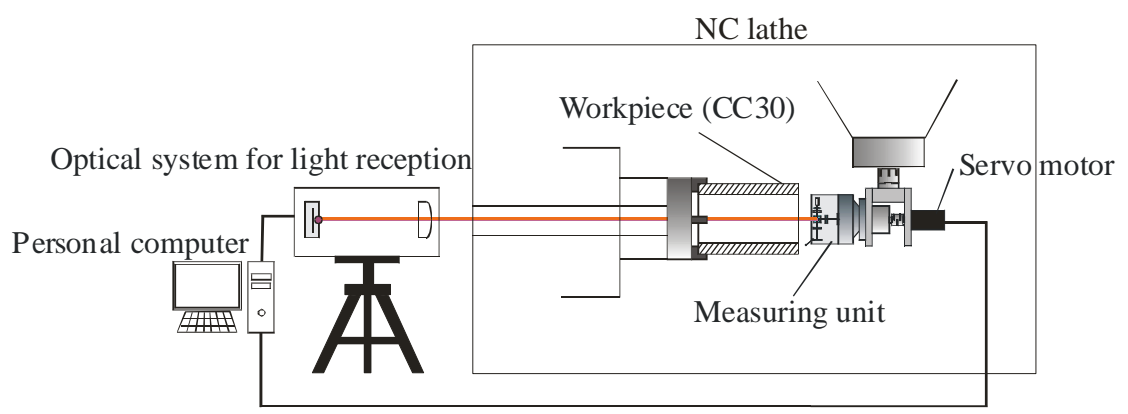

Figure 9: Experimental system for measuring a workpiece (CC30).

image-processing threshold, while the vertical axis shows the deviation of the spot on the CCD. Based on these results, an image-processing threshold of 60 was used, since it produces a small error.

\subsubsection{Dynamic Characteristics of the Feeler}

The mechanical probing frequency of the feeler to the wall surface is about $113 \mathrm{~Hz}$ and its measuring force is about $140 \mathrm{mN}$. The measurement's sampling frequency is limited by the image acquisition frequency of the CCD, since the frame rate of the CCD is about $30 \mathrm{~Hz}$. It is necessary that the rotational speed of the main shaft $\mathrm{N}$ satisfies Eqn. (2), when the number of required measuring mountain for the measured hole is set to $\mathrm{n}$.

$\mathrm{N}<1800 / \mathrm{n}$

\subsection{Experiments measuring a workpiece}

An experiment is performed by using an NC lathe (MAZAK, INTEGREX 200-III) to evaluate the system's measurement accuracy for roundness, straightness and cylindricity. Figure 9 shows a diagram of the experimental setup, while Fig. 10 shows a photograph of it. The measuring unit is installed on the spindle that is fixed in the bearing holder. The spindle is coupled to a servomotor by a coupling. A workpiece (CC30) containing a hole (diameter: $110 \mathrm{~mm}$; depth: $200 \mathrm{~mm}$ ) is measured (Fig. 11). It has a thin wall $(0.8 \mathrm{~mm}$ after machining) between hole depths 60 and $140 \mathrm{~mm}$ on the $+X$ side.

\subsubsection{Roundness}

The hole is measured at a rotation rate of $1 \mathrm{~min}^{-1}$ and a sampling frequency of $25.6 \mathrm{~Hz}$. A cutoff filter is not used. The value and shape of the hole's roundness are compared to those measured by a roundness tester.

Figures 12(a) and (b) show the roundness of the machined hole measured by the measuring unit and a roundness tester (TALYROND 252, Rank Taylor Hobson) at a depth of $10 \mathrm{~mm}$, respectively. The values of the roundness are $5.86 \mu \mathrm{m}$ when measured by the measuring unit and $6.85 \mu \mathrm{m}$ when measured with the roundness tester, respectively. Figures 12(c) and (d) show the measurement of the roundness at a depth of $100 \mathrm{~mm}$. The values are $30.65 \mu \mathrm{m}$ by the measuring unit and $31.21 \mu \mathrm{m}$ by the roundness tester. Their shapes and values correspond well with each other. Figure 13 shows the variation in the roundness measured by the measuring unit and by the roundness tester with hole depth. The values determined using both instruments are almost the same as each other.

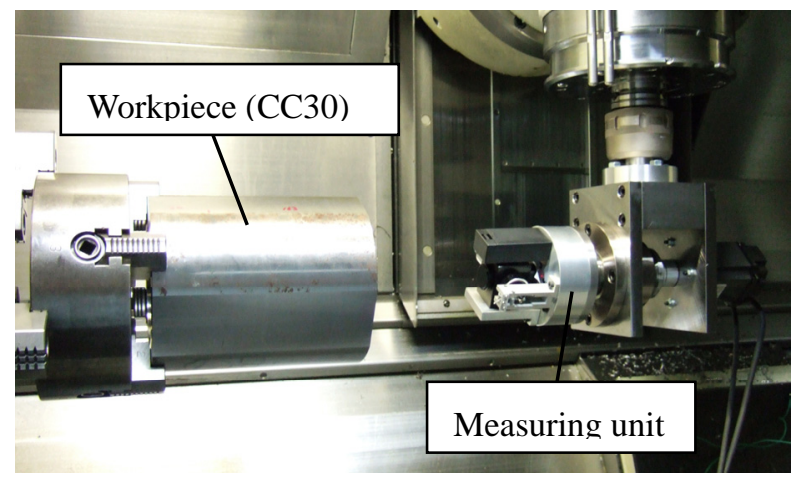

Figure 10: Photograph of the experimental apparatus.

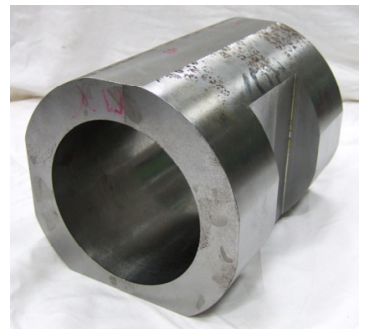

Figure 11: Workpiece (CC30).

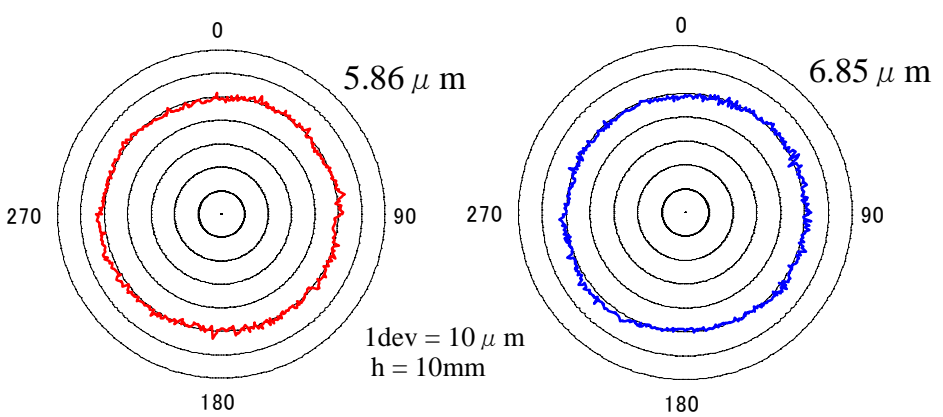

(a) By the measuring unit

(b) By a roundness tester

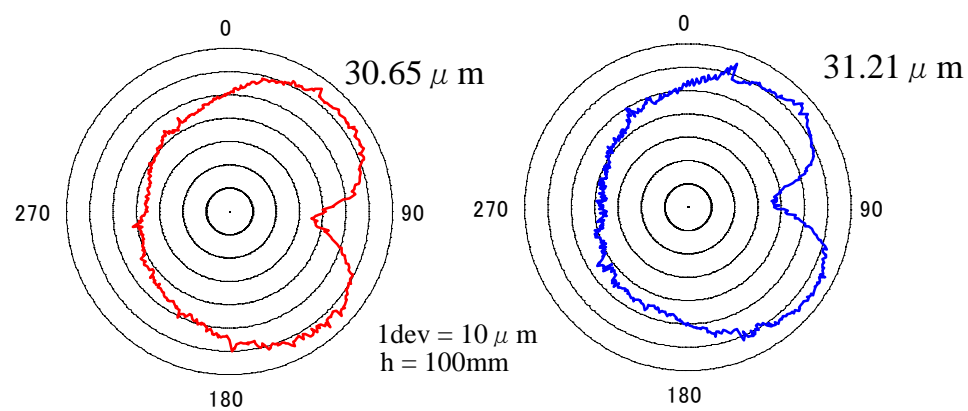

$\begin{array}{ll}\text { (c) By the measuring unit } & \text { (d) By a roundness tester }\end{array}$

Figure 12: Comparison of roundness by the measuring unit and roundness tester. 


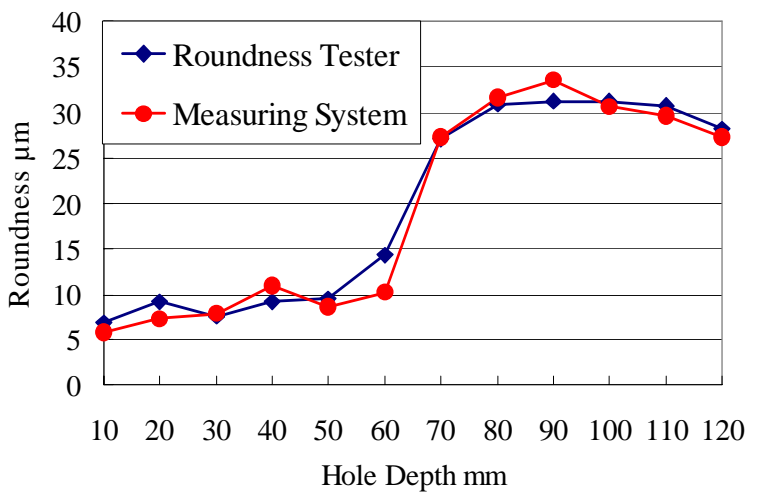

Figure 13: Variations in roundness measured by the measuring unit and by a roundness tester with hole depth.

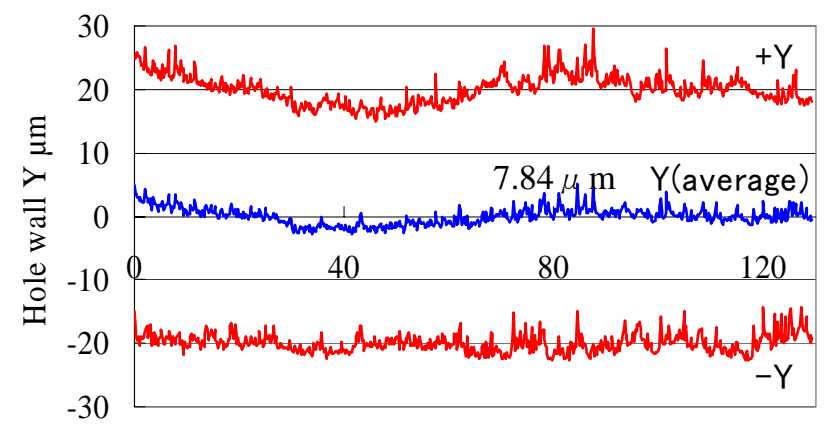

Hole Depth mm

(a) By the measuring unit

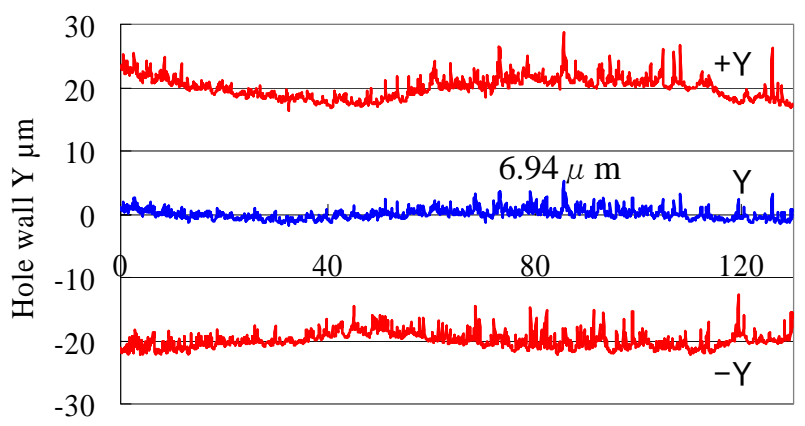

Hole Depth mm

(b) By the roundness tester

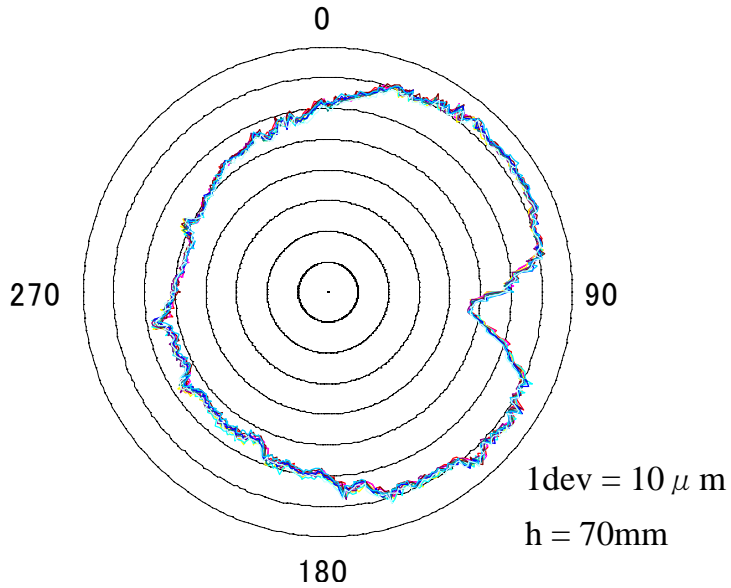

Figure 14: Ten measured values of roundness.

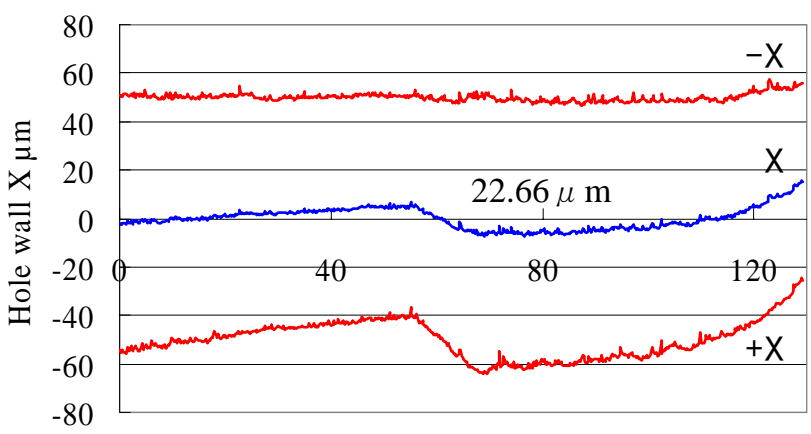

Hole Depth mm

(c) By the measuring unit

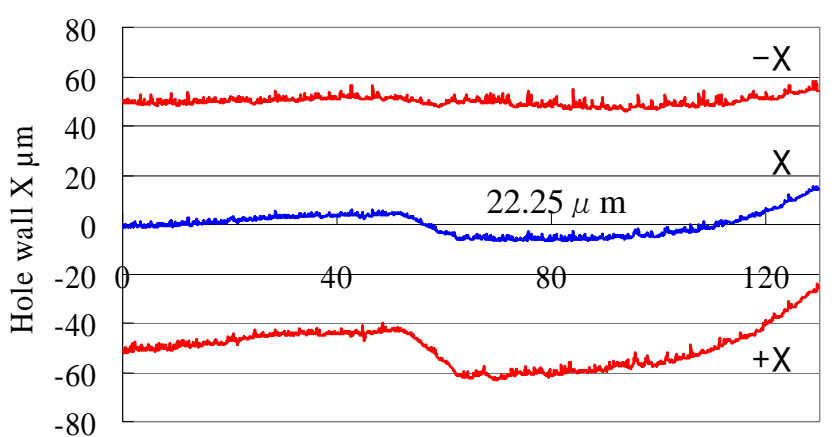

Hole Depth mm

(d) By the roundness tester

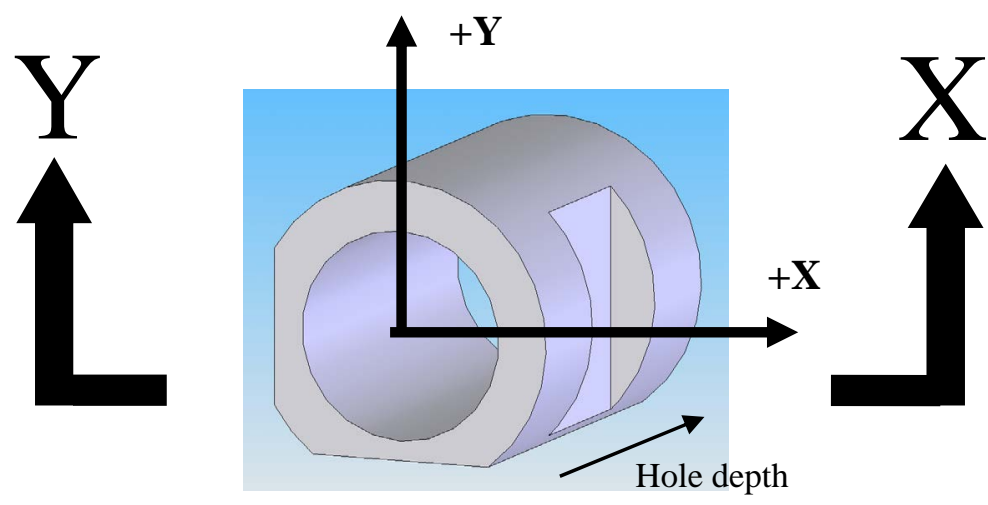

Figure 15: Comparison of hole walls measured by the measuring unit and by a roundness tester. 


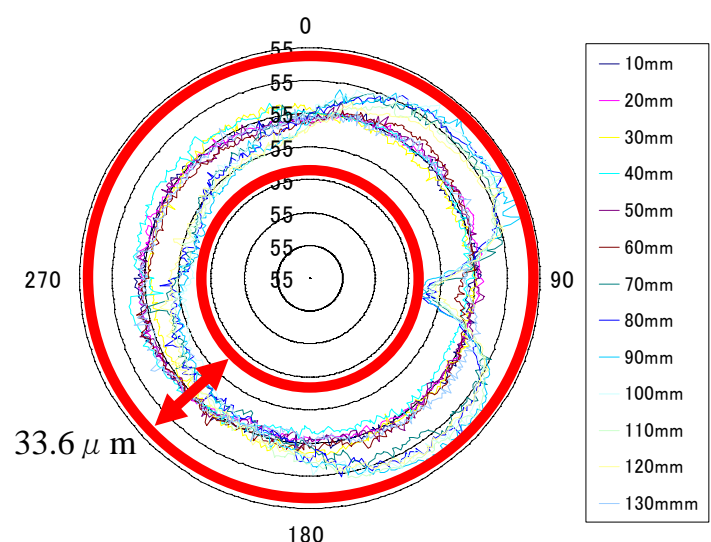

180

(a) By the measuring unit

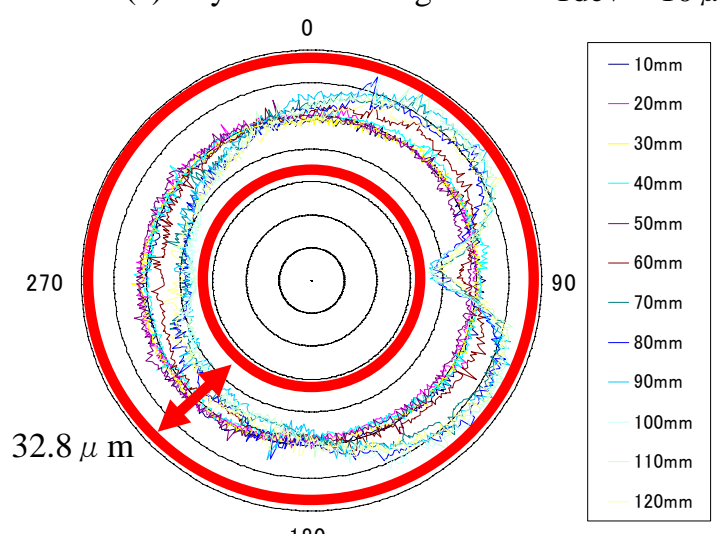

(b) By the roundness tester

Figure 16: Comparison of the roundness of the machined hole measured at depth intervals of $10 \mathrm{~mm}$ by the measuring unit and roundness tester.

\subsubsection{Repeatability of Roundness}

Figure 14 shows the values of roundness, which are measured 10 times at a depth of $70 \mathrm{~mm}$ and superimposed. Their standard deviation is $\pm 0.19 \mu \mathrm{m}$.

\subsubsection{Straightness}

The measuring unit held in the system's spindle is fed at a rate of $100 \mathrm{~mm} / \mathrm{min}$. Figures 15(a) and (b) show the hole walls in the $+X$ and $-X$ directions measured by the measuring unit and roundness tester with hole depth, respectively. The straightness is determined by taking an average line of the two hole walls.

The straightness of the hole in the $X$ direction is 22.66 $\mu \mathrm{m}$ when measured by the measuring unit and $22.25 \mu \mathrm{m}$ when measured by the roundness tester.

In the same way, the straightness in the $Y$ direction is $7.84 \mu \mathrm{m}$ when measured by the measuring unit and 6.94 $\mu \mathrm{m}$ when measured by the roundness tester. These values correspond well with each other.

\subsubsection{Cylindricity}

Figures 16(a) and (b) show the roundness of the machined hole measured at depth intervals of $10 \mathrm{~mm}$ by the measuring unit and roundness tester, respectively. The cylindricity is $33.6 \mu \mathrm{m}$ when measured by the measuring unit and $32.8 \mu \mathrm{m}$ when measured by the roundness tester. These values correspond well with each other.

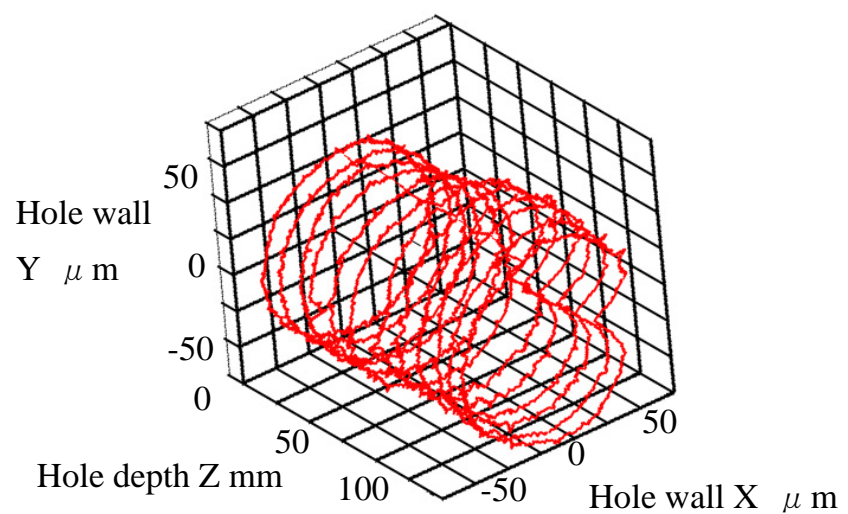

Figure 17: Hole shape scanned at depth intervals of 10 $\mathrm{mm}$ by the measuring unit.

Figure 17 shows the hole shape, which is obtained by scanning the hole wall at depth intervals of $10 \mathrm{~mm}$ in a circumferential direction.

\section{Conclusion}

The autocollimation principle is applied to a measuring system for determining the accuracy of a deep hole. Its performance is examined by measuring the resolution of the measuring system, roundness, straightness and cylindricity. The following findings are found.

1. The resolution of the measuring system is $0.076 \mu \mathrm{m}$ over a measurement range of $0.25 \mathrm{~mm}$.

2. The accuracy of the roundness, straightness, cylindricity measured by the measuring system corresponds well to that of roundness tester in terms of both shape and value.

3. The standard deviation of ten measured values of roundness is $0.19 \mu \mathrm{m}$.

\section{Acknowledgement}

The authors would like to thank Mr. Tokumitsu and Mr. Arita (Kyushu Electro Technology Corporation) for their cooperation.

\section{References}

[1] Katsuki, A., Onikura, H., Sajima, T., Park, H.K., Zhen, J.G, Murakami, H.: Development of a practical high performance laser-guided deep-hole boring tool: boring of steel workpieces, Proceedings of ASPE 2005 Annual Meeting, 56, (2005) 926.

[2] Stürenburg, H.O.: Ermittlung des Bohrungsverlaufs mit Hilfe des Ultraschallmeßverfahrens, Industrie Anzeiger, 104, 11, (1982) 96.

[3] Ohba, T., Inoue, H.: Development of a new device for measuring inner bore of pipe, Proceedings of the Meeting on Engineering and Technology in Basic Research, 1, (1999) 13.

[4] Ueki, M., Ooiwa, A.: An Interferometer for Inner Diameter Measurement of Cylinders, Bull. Japan Soc. of Prec. Engg., 21, 1 (1987) 3.

[5] Katsuki, A., Murakami, H, Onikura, H., Sajima, T.: Development of a Laser-Guided Deep-Hole Measuring System -Autocollimation System-, Proceedings of the $11^{\text {th }}$ International Conference on Precision Engineering (ICPE11), (2006)77-82. 